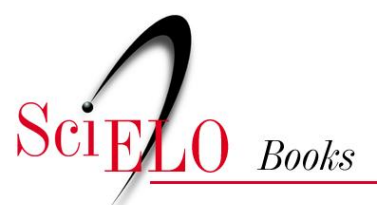

\title{
A subfamília Pentatominae
}

\author{
Thereza de Almeida Garbelotto \\ Luiz Alexandre Campos
}

\section{SciELO Books / SciELO Livros / SciELO Libros}

GARBELOTTO, TA., and CAMPOS, LA. A subfamília Pentatominae. In: Pentatominae do Sul de Santa Catarina [online]. Curitiba: Sociedade Brasileira de Zoologia, 2014, pp. 7-8. Zoologia: guias e manuais de identificação series. ISBN 978-85-98203-08-9. Available from SciELO Books $<\underline{\text { http://books.scielo.org }>\text {. }}$

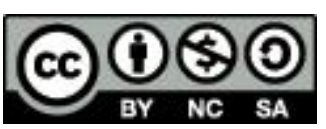

All the contents of this chapter, except where otherwise noted, is licensed under a Creative Commons Attribution-Non Commercial-ShareAlike 3.0 Unported.

Todo o conteúdo deste capítulo, exceto quando houver ressalva, é publicado sob a licença Creative Commons Atribuição Uso Não Comercial - Partilha nos Mesmos Termos 3.0 Não adaptada.

Todo el contenido de este capítulo, excepto donde se indique lo contrario, está bajo licencia de la licencia Creative Commons Reconocimento-NoComercial-CompartirIgual 3.0 Unported. 


\section{A subfamília Pentatominae}

Os insetos da ordem Hemiptera, vulgarmente chamados percevejos, constituem um grupo de insetos grande e diversificado (Triplehorn \& Johnson 2011). A maioria das espécies é terrestre e existem espécies aquáticas; muitos se alimentam da seiva de plantas, alguns sendo pragas sérias de plantas cultivadas; outros são predadores e muitos destes são benéficos à agricultura; e outros ainda atacam o homem e outros animais, sendo alguns destes vetores de doenças (Triplehorn \& Johnson 2011, Grazia et al. 2012).

Os hemípteros são caracterizados principalmente pela estrutura das peças bucais que são do tipo 'picador-sugador', apresentando o lábio articulado (Triplehorn \& Johnson 2011). A subordem Heteroptera constitui o maior e mais diverso grupo de insetos com metamorfose incompleta, sendo encontrados em todos os continentes (Schuh \& Slater 1995). As asas anteriores de Heteroptera são bastante características e denominadas hemiélitros, cuja parte basal é espessada e coriácea e a apical, membranosa; as asas posteriores são inteiramente membranosas (Triplehorn \& Johnson 2011).

Pentatomidae é a quarta família mais numerosa e diversa de Heteroptera, com 896 gêneros e 4.722 espécies, e ampla distribuição mundial (Schuh \& Slater 1995; Grazia \& Fernandes 2012; Rider 2011). Estes insetos são popularmente conhecidos como percevejo-do-mato, percevejo-fedorento, percevejo-verde, frade, fede-fede e Maria-fedida. São chamados assim por produzirem um odor desagradável através de suas glândulas de cheiro, que nos adultos se abrem na região ventral do tórax próximo às pernas, e nas ninfas no dorso do abdômen (Panizzi et al. 2000). São reconhecidos facilmente por suas antenas geralmente com cinco segmentos, escutelo amplo e triangular que se estende até a base da membrana dos hemiélitros, esses sempre mais ou menos visíveis, e tamanho variando de 4 a 20 mm (Costa Lima 1940; Schuh \& Slater 1995; Grazia \& Fernandes 2012).

A subfamília Pentatominae, alvo deste guia, é a mais diversa e abundante de Pentatomidae, com 3.336 espécies reunidas em 621 gêneros no mundo e aproximadamente 338 espécies e mais de 70 gêneros no Brasil (Grazia \& Schwertner 2011; Rider 2011). É também a subfamília mais frequentemente coletada e que apresenta o maior número de espécies consideradas pragas de plantas cultivadas. Estes percevejos variam na forma e coloração do corpo, podem apresentar os ângulos umerais do pronoto desenvolvidos e o escutelo não atinge o ápice do abdômen (Fig. 2). Com ampla distribuição mundial, o grupo tem uma grande representatividade na região Neotropical (Schuh \& Slater 1995; Grazia et al.1999; Grazia \& Fernandes 2012).

A classificação de Pentatominae apresenta algumas diferenças conforme o autor consultado, podendo ser dividida desde oito até 42 tribos. Schuh \& Slater (1995) reconhecem oito tribos, Grazia et al.(1999) e Grazia \& Fernandes (2012) reconhecem nove tribos, e Rider (2011) reconhece 42 tribos, sendo 33 delas formadas por gêneros incluídos em Pentatomini em classificações anteriores.

A classificação de tribos de Pentatominae utilizada neste guia é a apresentada por Rider (2011). Devido à inexistência de chaves de identificação para as tribos, estas e as 52 espécies aqui incluídas estão organizadas alfabeticamente. As fotografias foram tomadas de espécimes conservados a seco e as escalas representam $1 \mathrm{~mm}$.

Para confirmar se o percevejo que você tem em mãos pertence à Pentatominae consulte a chave para subfamílias de Pentatomidae que ocorrem no Brasil apresentada a seguir. 
Chave para subfamílias de Pentatomidae (Modificada de: Rolston \& McDonald 1979; e Grazia \& Fernandes 2012).

1. Primeiro artículo do rostro robusto, estendendo-se bem além das búculas. Ou tíbia anterior foliácea Asopinae

- Primeiro artículo do rostro pouco alargado, repousando entre as búculas (ainda que, frequentemente seja mais longo do que as búculas). Tíbia anterior pouco expandida

2. Metasterno projetado anteriormente sobre o mesosterno ou raramente até o prosterno, formando um processo metasternal bifurcado anteriormente. Rostro não ultrapassando as mesocoxas Edessinae

- Mestasterno raramente projetado anteriormente até o mesosterno, nesse caso o rostro se estende até o abdomen. Rostro usualmente alcançando pelo menos as mesocoxas 3

3. Escutelo amplo e dotado de protuberância dorsal espinhosa. .Cyrtocorinae

- Escutelo de tamanho variável, sem protuberância dorsal

4. Rostro origina-se sobre ou posteriormente à linha transversal tangente ao limite anterior dos olhos Discocephalinae

- Rostro origina-se anteriormente à linha transversal tangente ao limite dos olhos......Pentatominae

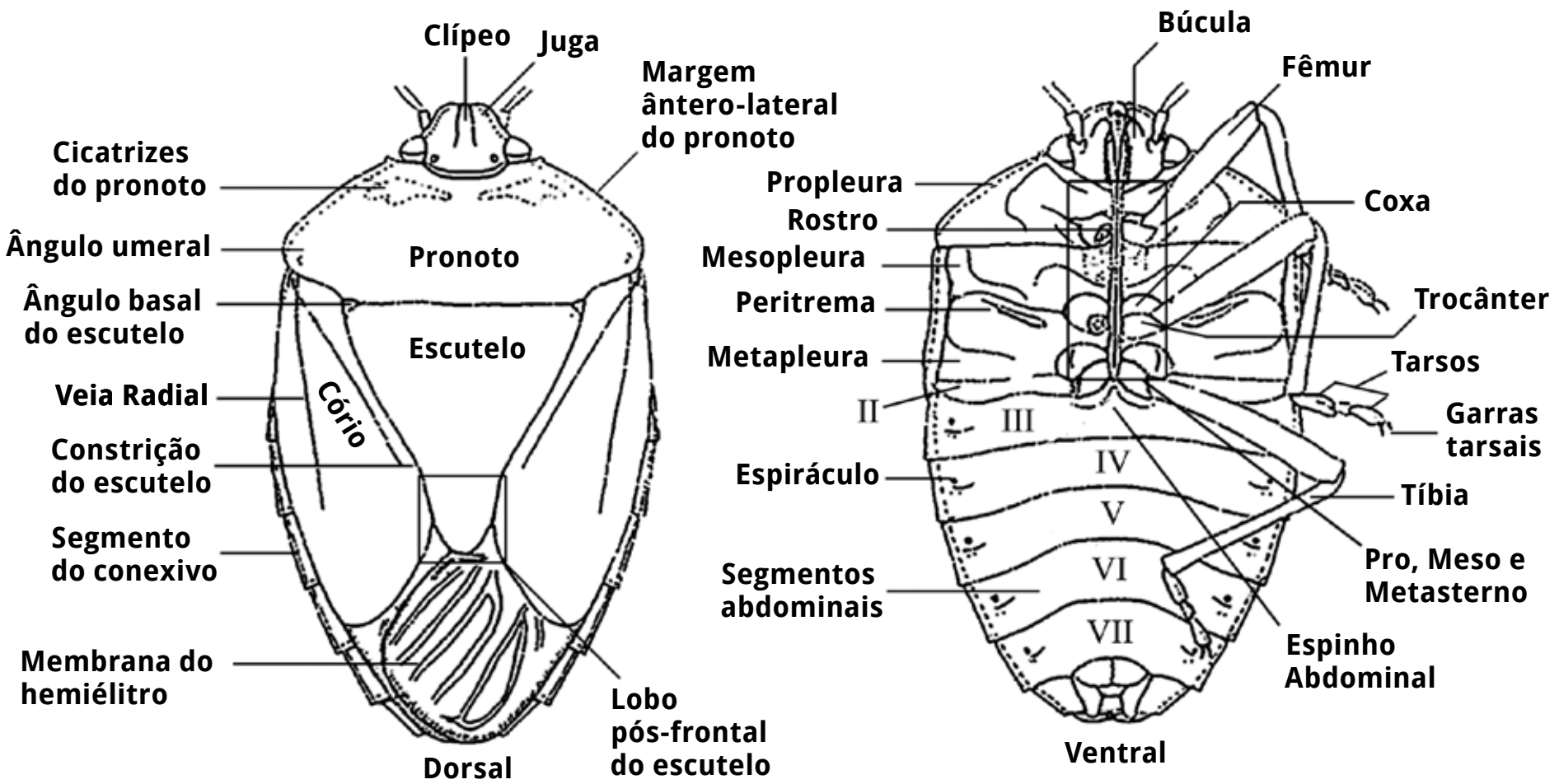

Figura 2: Esquema da morfologia de um pentatomídeo. Modificado de Schwertner \& Grazia, 2007. 